\title{
Evidence for free-living Bacteroides in Cladophora along the shores of the Great Lakes
}

\author{
Richard L. Whitman, Muruleedhara N. Byappanahalli*, Ashley M. Spoljaric, \\ Kasia Przybyla-Kelly, Dawn A. Shively, Meredith B. Nevers
}

United States Geological Survey, Great Lakes Science Center, Lake Michigan Ecological Research Station, 1100 North Mineral Springs Road, Porter, Indiana 46304, USA

\begin{abstract}
Bacteroides is assumed to be restricted to the alimentary canal of animals and humans and is considered to be non-viable in ambient environments. We hypothesized that Bacteroides could persist and replicate within beach-stranded Cladophora glomerata mats in southern Lake Michigan, USA. Mean Bacteroides concentration (per GenBac3 Taqman quantitative PCR assay) during summer 2012 at Jeorse Park Beach was 5.2 log calibrator cell equivalents (CCE) $\mathrm{g}^{-1}$ dry weight (dw), ranging from 3.7 to 6.7 . We monitored a single beach-stranded mat for $3 \mathrm{wk}$; bacterial concentrations increased by $1.6 \log \mathrm{CCE} \mathrm{g}^{-1} \mathrm{dw}$ and correlated significantly with ambient temperature $(p=0.003)$. Clonal growth was evident, as observed by $>99 \%$ nucleotide sequence similarity among clones. In in vitro studies, Bacteroides concentrations increased by $5.5 \log \mathrm{CCE} \mathrm{g} \mathrm{g}^{-1}$ after $7 \mathrm{~d}\left(27^{\circ} \mathrm{C}\right)$ in fresh Cladophora collected from rocks. Partial sequencing of the 16S rRNA gene of 36 clones from the incubation experiment showed highly similar genotypes ( $\geq 97 \%$ sequence overlap). The closest enteric Bacteroides spp. from the National Center for Biotechnology Information database were only 87 to $91 \%$ similar. Genomic similarity, clonality, growth, and persistence collectively suggest that putative, free-living Bacteroides inhabit Cladophora mats of southern Lake Michigan. These findings may have important biological, medical, regulatory, microbial source tracking, and public health implications.
\end{abstract}

KEY WORDS: Anaerobic environments $\cdot$ Bacteroides $\cdot$ Cladophora $\cdot$ Sequencing $\cdot$ Uncultured bacteria

Resale or republication not permitted without written consent of the publisher

\section{INTRODUCTION}

Bacteroides are mutualistic, gram negative, nonspore-forming bacteria that are well represented in the intestinal microflora of mammals, with cell densities as high as $10^{10}$ to $10^{11} \mathrm{~g}^{-1}$ feces in humans (Madigan et al. 2003). While mutualistic, Bacteroides may become opportunistic pathogens; several species within the Bacteroides fragilis group have been linked to various diseases and clinical manifestations, such as bacteremia and colonic, skin and softtissue infections (Wexler 2007). Although there are about 20 described species of Bacteroides (Shah \& Collins 1989, Wexler 2007), it is generally believed that many more species remain undescribed due to culturing difficulties. Species of unknown viability and origination are listed in the National Center for Biotechnology Information (NCBI) database from various environments, such as sludge, rivers, sediments, and biofilms; we know of no species found that are unique to any environmental matrix. Bacteroides are strict anaerobes, but some tolerance to low oxygen concentrations has been noted for select species within the $B$. fragilis group (Baughn \& Malamy 2004).

There are many environmental habitats that can be characterized as anaerobic, aphotic, and warm, with adequate nutrients (glycans) for Bacteroides suste- 
nance. Bacteroides are efficient users of polysaccharides of complex carbohydrates (see review by Hooper et al. (2002)), and previous laboratory studies have shown that they can utilize polysaccharides associated with algae (Michel \& Macfarlane 1996, Bakunina et al. 2012, Hehemann et al. 2012). High levels of other fecal indicators and some pathogens, such as Clostridium perfringens, C. botulinum, Escherichia coli, enterococci, Campylobacter, and Salmonella, are common in Cladophora mats in the Great Lakes (Byappanahalli et al. 2003, Whitman et al. 2003, Byappanahalli \& Whitman 2009, Verhougstraete et al. 2010).

The objectives of this study were to determine whether conditions in Cladophora mats promoted in situ and in vitro replication of Bacteroides and to identify strain(s) most likely to thrive in these algal mats. We used Cladophora as a model to test whether Bacteroides can develop viable populations in nutrient-rich, anaerobic algal matter, and we discuss the biological, public health, and environmental implications of our findings.

\section{MATERIALS AND METHODS}

\section{Study area}

Jeorse Park (JP) Beach is located on the southwest shore of Lake Michigan in East Chicago, Indiana, USA $\left(41.651110^{\circ} \mathrm{N}, 87.433422^{\circ} \mathrm{W}\right)$, in a highly industrialized area. The beach is bounded by 2 breakwalls, which act as substrates for Cladophora growth and also help to direct algae along the shoreline where they accumulate in shallow water or become stranded on the beach.

For one in vitro growth experiment, we collected attached algae from a breakwall at Portage Lakefront and Riverwalk (PL), an Indiana Dunes National Lakeshore beach, located in Portage, Indiana, USA $\left(41.631170^{\circ} \mathrm{N}, 87.179369^{\circ} \mathrm{W}\right)$. All other sampling and experiments occurred at JP.

\section{Sample collection}

Between 27 June and 25 September 2012, samples from stranded algal mats were collected at varying frequencies, from 1 to 3 times a week for a total of 15 sampling occasions. Due to the transient nature of Cladophora mats along the shore, the sampling location varied somewhat $(<150 \mathrm{~m})$. Photos of the algal mats were taken frequently to document their temporal duration; it was established that between 21 August and 11 September the same mat was present on the Jeorse Park shore. Cladophora glomerata (L.) Kutz dominated the mats (95\%), but incidental Chara, Spirogyra, and Mougeotia occurrence was noted. Sampling occurred before 11:00 h CDT to reduce solar insolation effects and interference from beach visitors. Triplicate samples (200 to $400 \mathrm{~g}$ wet weight) were collected with nitrile-gloved hands and placed into sterile polyethylene bags. Samples were transported to the laboratory in a cooler on ice, stored at $4^{\circ} \mathrm{C}$, and processed within $24 \mathrm{~h}$. Continuous measurements of air temperature were collected from an on-site weather station located at 63rd Street Beach, Chicago, Illinois, $20 \mathrm{~km}$ NNW of the study beach. Means of the highest and lowest temperature readings within the $24 \mathrm{~h}$ period were calculated.

\section{In vitro incubation studies}

For an in vitro growth study (incubation study I), Cladophora was collected in September 2012 at PL. Approximately $2 \mathrm{~kg}$ (wet weight) of algae attached to rocks was collected. The Cladophora was handmixed in a sterile container, and five 11 sterile bottles were each filled with $400 \mathrm{~g}$. With the exception of time 0 (D0), bottles were incubated in the dark at $27^{\circ} \mathrm{C}$; caps were loose-fitting to allow gas exchange. Samples were analyzed at D0 and after $7,14,21$, and 28 d of incubation (D7, D14, D21, and D28). Two small containers filled with water were kept in the incubator to minimize moisture loss from the samples.

To demonstrate reproducibility, a second in vitro experiment (incubation study II) was performed, in which Cladophora samples from the seasonal JP collection, which had been stored at $-20^{\circ} \mathrm{C}$, were thawed and used. Samples from 3 distinct time periods were chosen: 27 June, the first decaying mat of the season; 21 August, the first day of a long-term mat; and 30 August, the peak concentration of BaCteroides quantitative PCR (qPCR) calibrator cell equivalents (CCE) during the season. Three replicates representing each date were individually homogenized with a sterile spatula for $1 \mathrm{~min}$, and subsamples $(10 \mathrm{~g})$ were transferred into $15 \mathrm{ml}$ tubes ( 3 tubes per replicate, total of 27 tubes). Tubes were covered with parafilm tape, and a pin-pricked hole allowed gas exchange; all tubes, with the exception of D0, were incubated at $27^{\circ} \mathrm{C}$ in the dark. Samples were analyzed at D0 and after 3 and $9 \mathrm{~d}$ of incubation 
(D3 and D9). A beaker filled with water was placed in the incubator to minimize sample moisture loss during incubation.

\section{Sample processing}

Seasonal

Sample replicates were homogenized with sterile spatulas, and subsamples (25 g) were placed into dilution bottles and combined with $100 \mathrm{ml}$ phosphatebuffered water (PBW; pH 7.0 \pm 0.2 ) containing $0.01 \%$ hydrolyzed gelatin (Ishii et al. 2006). Samples were shaken twice for 2 min $30 \mathrm{~s}$, with a 1 min resting period in between; the mixtures were then transferred to sterile $50 \mathrm{ml}$ centrifuge tubes and centrifuged $(622 \times g)$ for $1 \mathrm{~min}$. The resulting supernatants were decanted into sterile dilution bottles, aliquots $(40 \mathrm{ml})$ from the 3 replicates were combined, and $15 \mathrm{ml}$ of the composite was filtered through $0.4 \mu \mathrm{m}$ polycarbonate membranes for qPCR analyses (see 'qPCR assay' below). Sample wet-to-dry-weight ratios were determined individually after drying algal subsamples $(5 \mathrm{~g})$ at $105^{\circ} \mathrm{C}$ for $24 \mathrm{~h}$, and the mean ratio was used for calculating cell densities $\mathrm{g}^{-1}$ dry weight (dw).

\section{In vitro incubation studies}

For incubation study I, $300 \mathrm{ml}$ of PBW containing $0.01 \%$ hydrolyzed gelatin was added to each of the 5 bottles containing $400 \mathrm{~g}$ algae and placed on an orbital shaker for $30 \mathrm{~min}$ at $200 \mathrm{rpm}$. The liquid extracts elutriated from algae were transferred to $50 \mathrm{ml}$ centrifuge tubes and centrifuged at $622 \times g$ for $1 \mathrm{~min}$; the supernatants were then decanted into new tubes to be used for further processing. For incubation study II, the sample tubes were thawed and the contents emptied into sterile dilution bottles; $50 \mathrm{ml}$ of PBW containing $0.01 \%$ hydrolyzed gelatin was added to each bottle. Samples were then shaken and centrifuged using the same procedure described previously under the seasonal samples.

\section{Molecular analyses}

For molecular analysis, aliquots of extracts (5 to $15 \mathrm{ml}$ ) elutriated from algae were filtered through $0.4 \mu \mathrm{m}$ polycarbonate filters (Millipore). Filters were immediately stored in $2 \mathrm{ml}$ semi-conical, screw cap centrifuge tubes and stored at $-80^{\circ} \mathrm{C}$ until processing.

\section{DNA extraction}

Filters were thawed and transferred to PowerBead tubes, and DNA was extracted using the PowerSoil ${ }^{\circledR}$ DNA extraction kit (MO BIO Laboratories) as per the manufacturer's instructions, with the following modifications: to each tube, $11.8 \mu$ l of salmon testes DNA (Sigma-Aldrich), $0.2 \mu \mathrm{g} \mathrm{ml}{ }^{-1}$ final concentration, was added to the supernatant following the bead-beating step as an internal control and reference for qPCR amplification. Testing has shown (Powersoil ${ }^{\circledR}$ only) that adding the internal control pre- and post-beadbeating step showed no significant difference $(\mathrm{p}=$ $0.215)$ between the threshold cycle number $\left(C_{t}\right)$ reference values (data not shown). Additionally, the final DNA elution step was repeated 3 times with 3 aliquots of elution buffer $(30,30$, and $40 \mu \mathrm{l})$.

The primers for PCR and qPCR assays in this study have been used previously to identify and characterize members within the order Bacteroidales (Bernhard \& Field 2000, US Environmental Protection Agency 2010). However, in the present study, we refer to our target bacteria as Bacteroides, since the BLAST analyses repeatedly confirmed that our sequences had similarities (in excess of 96\%) with those listed in the NCBI database originating from clinical or environmental samples, with the majority of them designated as genus Bacteroides from uncultured bacteria.

\section{qPCR assay}

Bacteroides densities in samples were determined using qPCR, as described elsewhere (US Environmental Protection Agency 2010). Amplification reactions were performed using a Bio-Rad CFX Connect instrument (Bio-Rad) in 96-well PCR plates, with a reaction volume of $25 \mu$ l containing $5 \mu$ l of $5 \times$ or $25 \times$ diluted DNA template. B. thetaiotaomicron (ATCC 29741) was used for developing a standard curve and calibrators. Bacteroides in test samples were quantified as CCE. Appropriate positive and negative controls, B. thetaiotaomicron, no templates (PCR water), and extraction blanks were included in all assays. Because of the complex nature of the samples tested in this study, we were not able to sufficiently decrease PCR inhibitors on certain samples from incubation studies (27\% of the total number of samples analyzed), as indicated by salmon reference values. Nonetheless, we are confident that the detected trends in CCE values are reliable, and the results were reproducible across experiments conducted in this study. 


\section{PCR assay and cloning}

PCR primers Bac32F and 708R were used to target an $\sim 700$ bp region of the 16S rRNA gene as previously described (Bernhard \& Field 2000). Briefly, reactions were carried out in a $25 \mu$ reaction mixture containing the following components: $1 \times$ PCR buffer, $1.5 \mathrm{mM}$ $\mathrm{MgCl}_{2}, 16 \mu \mathrm{g}$ bovine serum albumin, $200 \mu \mathrm{M}$ deoxynucleoside triphosphates, $0.25 \mu \mathrm{l}$ Taq Polymerase

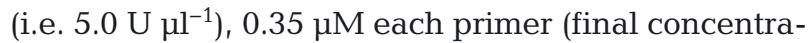
tion), and $2 \mu$ DNA template. The assay thermal cycling conditions were as follows: $3 \mathrm{~min}$ at $94^{\circ} \mathrm{C}$, followed by 35 cycles of $60 \mathrm{~s}$ at $94^{\circ} \mathrm{C}, 45 \mathrm{~s}$ at $53^{\circ} \mathrm{C}, 45 \mathrm{~s}$ at $72^{\circ} \mathrm{C}$, and a $7 \mathrm{~min}$ final extension at $72^{\circ} \mathrm{C}$. PCR amplifications were carried out on a Bio-Rad T100 Thermal Cycler (Bio-Rad), and PCR products were separated on a Lonza FlashGel ${ }^{\circledR}$ System (agarose gel, $2.2 \%$ w/v; Lonza Rockland). Following gel electrophoresis, PCR products were purified using the Wizard ${ }^{\circledR}$ SV Gel and PCR Clean-Up System (Promega). PCR products from 10 algal samples were chosen for sequencing: 6 from seasonal algal samples and 4 from incubation study I (D0, D7, D14, and D28).

Purified PCR products of D0 and D7 algal samples were cloned into the $\mathrm{pGeM}^{\circledR}$ - $\mathrm{T}$ Easy vector (Promega) according to the manufacturer's protocol. The vectors were then transformed into Escherichia coli cells (JM109 high efficiency). From each D0 and D7, 24 transformants were randomly selected and inoculated into $1 \mathrm{ml}$ Luria-Bertani freezing medium. The tubes were then incubated overnight on an orbital shaker (100 rpm) at $37^{\circ} \mathrm{C} .100 \mu$ aliquots were sent to the Genomics Core at Michigan State University for further processing and sequencing. Bacteroides thetaiotaomicron (ATCC 29741) served as our reference and control for all analyses.

\section{Phylogenetic analysis}

Sequencing was carried out using ABI BigDye Terminator v3.1 chemistry and POP-7 polymer, and sequencing reactions were carried out in both directions and run on an ABI Prism 3730xl DNA analyzer (Applied Biosystems). Sequence identity was verified using the NCBI BLAST program (http://blast.ncbi. nlm.nih.gov/). Three sequences had no significant similarity matches within the GenBank database, and thus, they were removed from the analysis. Trimmed sequences were aligned in MEGA5 using ClustalW. The evolutionary history was inferred by using the maximum likelihood method based on the Kimura 2-parameter model (Kimura 1980, Tamura et al. 2011). All positions with < $95 \%$ site coverage were eliminated. Bootstrap values were obtained from a consensus of 1000 resamplings; bootstrap values $<70 \%$ were removed.

\section{Statistical analyses}

Statistical analyses were performed using SPSS version 12.0 (SPSS 2003). Statistical procedures were performed on $\log _{10}$-transformed CCE data. The Kolmogorov-Smirnov test, a non-parametric test, was used to test parametric assumptions of equality of variance and normal distribution. Pearson correlation (Pearson's r) was reported for Bacteroides CCE and air temperature. Analysis of variance with a Tukey post-hoc test was used to examine the significance in Bacteroides CCE over time during in vitro incubation study II.

\section{RESULTS}

\section{Seasonal field sampling}

Mean concentrations of Bacteroides (log CCE $\mathrm{g}^{-1}$ $\mathrm{dw} \pm \mathrm{SE}$ ) in algal samples collected throughout the sampling season were $5.21 \pm 0.23(\mathrm{n}=15)$. The lowest and the highest concentrations, 3.72 and 6.73, were observed on 27 June and 30 August (Fig. 1). The wet-

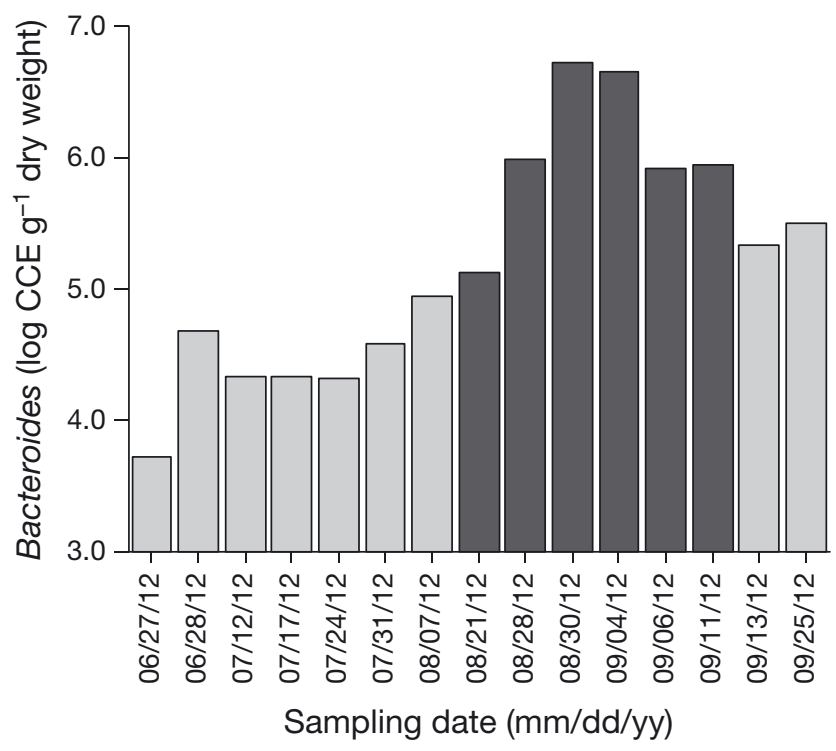

Fig. 1. Bacteroides concentrations (log calibrator cell equivalents [CCE] $\mathrm{g}^{-1}$ dry weight) eluted from algae collected from Jeorse Park Beach IN, USA (from 27 June to 25 September 2012). Dark gray bars represent samples collected from a stranded mat that persisted over $3 \mathrm{wk}$ 
to-dry ratio of the algal mat samples ranged from 2.06 to 11.28 . Notably higher concentrations were detected in samples from the same consistent algal mat stranded along the shoreline between 21 August and 11 September (Fig. 1, black bars). Bacterial concentrations were significantly correlated with mean daily air temperature during this time (Pearson $\mathrm{r}=$ 0.955, $\mathrm{p}=0.003, \mathrm{n}=6$ ).

\section{In vitro incubation studies}

The concentration of Bacteroides (log CCE g ${ }^{-1}$ wet weight) at D0 of incubation study I was 2.48 and increased to 8.01 at D7 of incubation (Fig. 2a). Concentrations remained at this level for the remaining sampling days (D14 and D28). For incubation study II, concentrations of Bacteroides (log CCE g ${ }^{-1} \mathrm{dw} \pm \mathrm{SE}$ ) at D0 ranged from $4.25 \pm 0.36$ (late June samples) to $5.67 \pm 0.13$ (late August samples) (Fig. 2b-d). In both August samples (21 and 30 August), concentrations increased significantly at D3 of incubation ( $p<0.001)$, but concentrations decreased in June samples. At D9, concentrations of Bacteroides were significantly higher in all samples relative to D0 measurements ( $p<0.001)$, with the highest concentration observed in the 30 August sample: $8.79 \pm 0.04$. In both incubation studies, there was evidence of inhibition as noted by salmon $C_{t}$ values (i.e. D7, D14, and D28 from incubation study I; all 3 replicates from D3 and D9 from 27 June sample in incubation study II; 1 replicate each from 21 and 30 August samples). Although the final CCE in these samples may have been affected by the presence of inhibitors, the increasing trend detected over time was conserved.

\section{Sequencing}

Bacterial sequences of the samples from our seasonal field sampling were $99 \%$ identical. Otherwise, partial sequences of the 16S rRNA gene from seasonal field sampling at JP were related to Bacteroides from 2 human and 8 non-human sources. Top matches from the GenBank database included: Bacteroides sp. (98 to $99 \%$ identity) isolated from a granulated sewage sludge in Japan (GenBank AB787271); uncultured Bacteroidales strains (98 to $99 \%$ identity) from a wastewater treatment plant in Ireland (EU573848); 6 uncultured Bacteroidales strains (97 to 98\% identity) from river water impacted by migratory sandhill cranes in Nebraska (KC149761; KC149831; KC149832; KC149834; KC149844; KC149845); uncultured Bac-
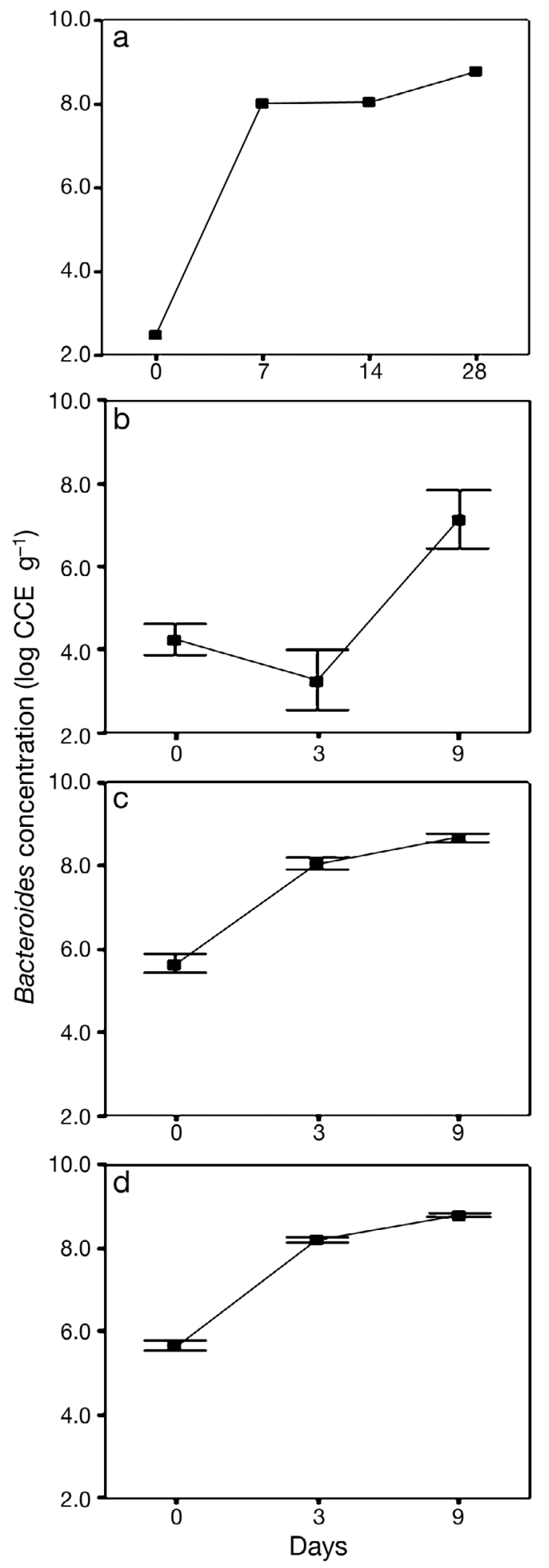

Fig. 2. (a) Bacteroides concentrations (log calibrator cell equivalents [CCE] g ${ }^{-1}$ wet weight) within Cladophora from Portage Lakefront Beach, IN, USA, on 17 September 2012 (incubation study I). (b-d) Log mean \pm 1 SE Bacteroides concentrations (log CCE g ${ }^{-1}$ dry weight) within Cladophora for samples taken on 27 June, 21 August, and 30 August 2012, respectively, at Jeorse Park Beach, IN, USA, (incubation study II) 
teroides sp. (98\% identity) from biofilm samples from a cave in Tennessee (JN820138); and uncultured bacteria belonging to Bacteroidales (98\% identity) from river water in Korea (GQ921905).

The 36 clones included in sequencing analyses from in vitro incubation study I were 98 to $100 \%$ identical to one another; however, 3 clusters were still observed: CLADOPHORA A (20 clones), CLADOPHORA B (5 clones), and CLADOPHORA C (11 clones) (Fig. 3).
Top matches from the GenBank database for bacterial sequences of D0 and D7 clones from in vitro incubation study I were nearly identical (97 to $99 \%$ similarity) to sequences from seasonal field sampling at JP. Bacterial sequences from D7, D14, and D28 of in vitro incubation study I were $99 \%$ identical among one another. Of the 21 Bacteroidales sequenced in the initial population, $24 \%$ matched Prevotella, but none were detected thereafter.

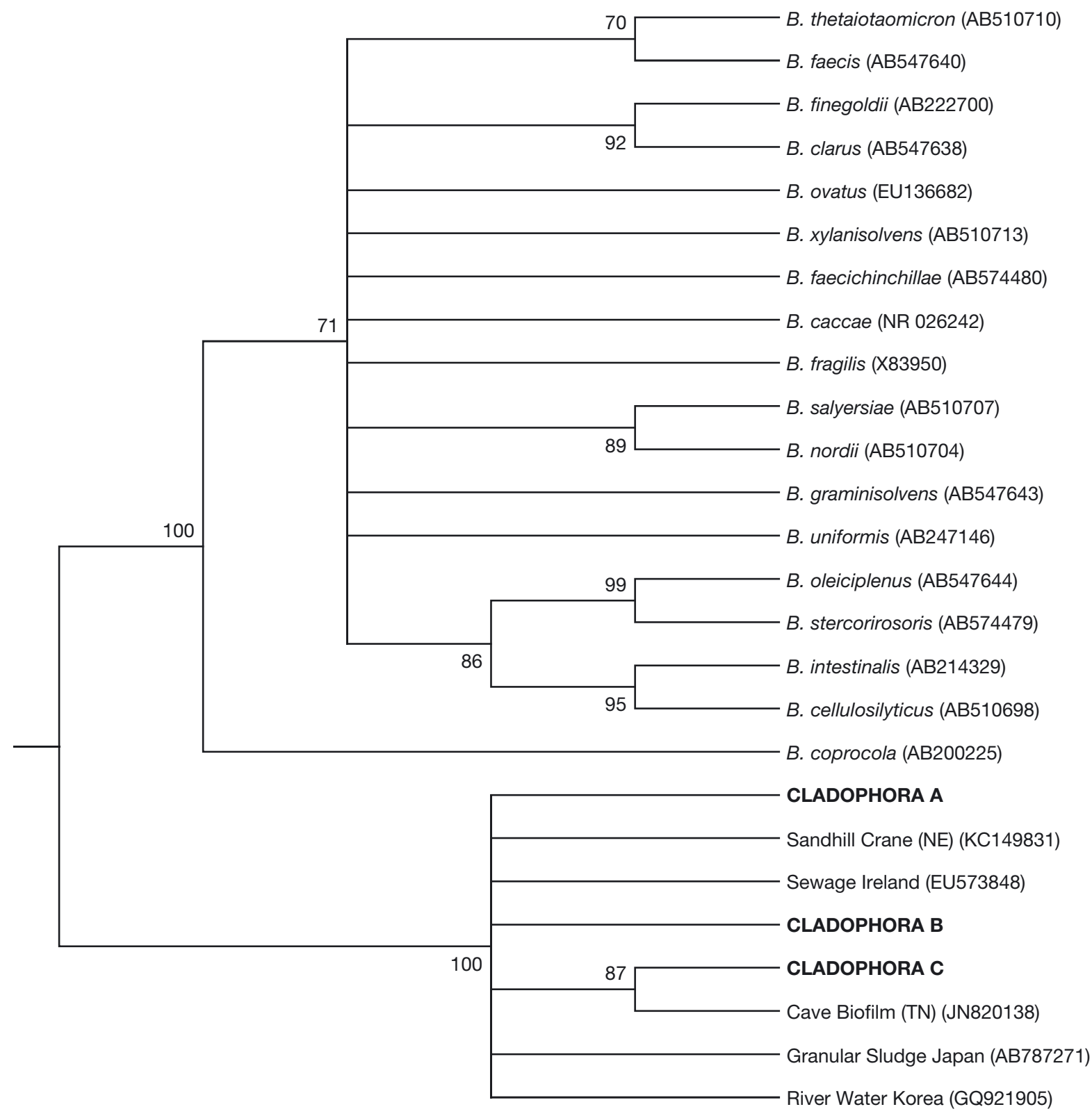

Fig. 3. An unrooted phylogenetic tree derived from partial 16S rRNA gene sequences (540 positions) obtained from Bacteroides spp. amplified from Cladophora samples. Cladophora A, B, and C represent a total of 36 clonal sequences. Sequences obtained from the GenBank database are designated by the species name and/or accession number. Bootstrap values are shown as percentages of 1000 trees; values $<70 \%$ are omitted 


\section{DISCUSSION}

Bacteroides is most commonly recognized as a commensal organism living in the mammalian enteron, and it is not generally considered free-living or capable of surviving more than a few hours in the ambient environment (Kreader 1998, Falkow et al. 2006, Layton et al. 2006, Ballesté \& Blanch 2010). We found no previous studies demonstrating that the bacteria were free-living and only a few studies suggesting that Bacteroides can replicate in non-enteric habitats. Walters \& Field (2006) detected actively growing Bacteroidales in laboratory mesocosms, and van der Wielen \& Medema (2010) acquired circumstantial evidence that gene copies of Bacteroides increase during pre-treatment of ground water. In this study, however, we followed viable populations both in natural and laboratory conditions over an extended period of time; these results may be the first evidence of sustained ambient multiplication of an environmentally occurring Bacteroides.

\section{Growth}

We observed a steady increase of $1.6 \log \mathrm{CCE} \mathrm{g^{-1 }}$ $\mathrm{dw}$ of clonal Bacteroides over $8 \mathrm{~d}$ in a single, persistent mat in August 2012, suggesting in situ growth rather than merely DNA accumulation from wildlife or sewage. BLAST analysis of our sequences showed a $99 \%$ similarity in genomic identity among these populations with the homogeneity maintained at this level, suggesting clonality of these Cladophoraassociated Bacteroides. Environmentally, we found no physical conditions that would limit the growth of these bacteria: the ambient high temperature was $26^{\circ} \mathrm{C}$ with a low of $19^{\circ} \mathrm{C}$; the surface temperature of the algal mat reached as high as $34^{\circ} \mathrm{C}$ (Fig. 4); Cladophora moisture content was $76 \% \mathrm{w} / \mathrm{w}$, with the stranded algae likely turning anaerobic within $1 \mathrm{~h}$ in vitro (J. Peller et al. unpubl.); $28.5 \%$ of the algae is made up of microfibrils of glucose, galactose, arabinose, and xylose (Wyatt et al. 2014). Seaman (2009) reports $359 \mathrm{mg} \mathrm{l}^{-1} \mathrm{NH}_{4}-\mathrm{N}, 3.8 \mathrm{mg} \mathrm{l}^{-1} \quad \mathrm{NO}_{3}-\mathrm{N}$, $5.5 \mathrm{mg} \mathrm{l}^{-1}$ available $\mathrm{P}$, and $366 \mathrm{mg} \mathrm{l}^{-1}$ available $\mathrm{K}$ in compost Cladophora. In our pilot experiments, concentrations of seeded $B$. thetaiotaomicron in decayed algae increased after 4 to $9 \mathrm{~d}$ of incubation in 26 to $35^{\circ} \mathrm{C}$ (data not shown), suggesting that Cladophora may be a suitable growth medium for this species as well.

Our observations at JP beach were followed by 2 laboratory validations of Bacteroides growth. A $5.5 \log \mathrm{CCE} \mathrm{^{-1 }}$ wet weight increase occurred at $27^{\circ} \mathrm{C}$ at D7 (incubation study I) and a $3 \log \mathrm{CCE} \mathrm{^{-1 } \mathrm { dw }}$ increase at D3 (incubation study II), with concentrations reaching 8 to $9 \log \mathrm{CCE} g^{-1}$ in both experiments, along with very low genomic diversity (sequence similarity $>97 \%$ ). Despite the very high concentrations detected by qPCR, we were unsuccessful at isolating and culturing this presumably unknown Bacteroides using formulated media.
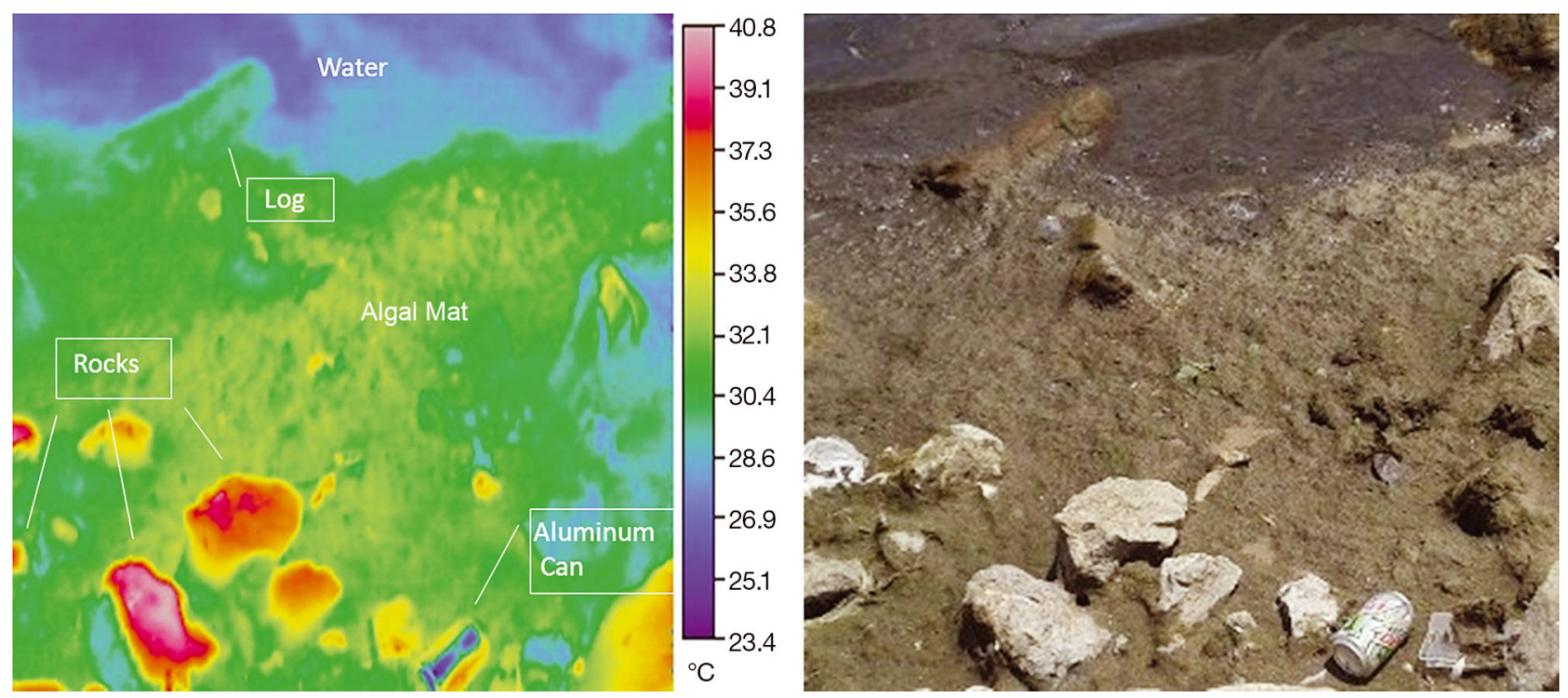

Fig. 4. Thermal (left) and digital (right) images of a portion of large mat of stranded Cladophora extending several hundred meters along the shore at Jeorse Park Beach IN, USA, on 27 June 2012. Note that the algae are detached and in advanced stages of decomposition 


\section{Persistence}

Short- to longer-term persistence of viable Bacteroides have been noted, principally in sewage and animal feces (e.g. Okabe \& Shimazu 2007, Bell et al. 2009, Walters \& Field 2009, Ballesté \& Blanch 2010, Liang et al. 2012). Most studies on Bacteroidales have been done in surface and groundwater environments. Some research, however, has been done in specialized microhabitats, such as Alpine soils (Vierheilig et al. 2012), shellfish samples from France (Mauffret et al. 2013), thick biofilm inside influent pipes (Savichtcheva et al. 2007), groundwater samples from the Netherlands (van der Wielen \& Medema 2010), sand (Yamahara et al. 2007, Yamahara et al. 2012, Eichmiller et al. 2013), and sediments (Vogel et al. 2007, LaPara et al. 2011, Eichmiller et al. 2013). In a detailed study by Olapade et al. (2006) of microbial communities associated with Cladophora mats in Lake Michigan, it was found that as much as $40 \%$ of clonal sequences belonged to the CytophagaFlavobacterium-Bacteroides group, and the authors concluded that Bacteroides may comprise a large portion of bacteria in Cladophora. In the present study, Bacteroides in stranded algae persisted under ambient conditions for 3 mo under varying hydrometeorological conditions typical of a temperate summer. During the season, Cladophora mats remained stranded, often returned to the lake, re-stranded, were occasionally covered in sand, and uncovered by the swash. While we follow Bacteroides on these ephemeral mats, we focused on 21 August to 11 September when the mat remained relatively stable and isolated from the lake. The seasonal presence of Bacteroides and evident clonality strengthens the belief that these bacteria are capable of maintaining their population through clonal growth; long-term persistence is also evident.

We suggest that Bacteroides populations recovered during our seasonal sampling at JP may be of nonenteric origin, since they were only 87 to $91 \%$ similar to fecal species of Bacteroides (Fig. 3) and the B. fragilis group, which is characteristic of human gut flora (Liu et al. 2003, Wexler 2007). Our comparisons with NCBI reference sequences showed 97 to $99 \%$ similarity to uncultured Bacteroides sp. This finding is supported by Bower et al. (2005) who reported unknown species of Bacteroides present in water samples in areas of unknown human waste input. Similarly, Bacteroides were detected in deep groundwater and tap water in the Netherlands with no history or evidence for fecal contamination (van der Wielen \& Medema 2010). Vierheilig et al. (2012) suggest persistence of some autochthonous, non-intestinal populations detected by AllBac and BacUni primers in Alpine soils, with no indication of human and animal fecal contamination; numbers approached fecal concentrations of 5 to 8 log CCE $\mathrm{g}^{-1}$. Finally, it has been concluded that Cladophora mats along beaches of Lake Michigan are comprised mostly of a phenotypically undescribed bacteria community, as 16S rRNA clones were unclassified and uncultured (Olapade et al. 2006).

The genetic similarity of our Bacteroides to those found in Korea, Japan, Ireland, and the USA may suggest that this presumed unknown species is cosmopolitan. These findings and the high confidence of clonal growth in the in vitro studies (98 to 99\% sequence similarity), along with field observations over the summer of 2012, support the hypothesis that at least some Bacteroides are capable of growing and persisting in nature outside of an animal host in the presence of Cladophora. The wider prevalence and persistence of Bacteroides of environmental origin or in such environmental reservoirs is currently not well understood.

\section{Implications}

Our proposition that Bacteroides can survive and multiply in the environment has important biological, ecological, and public health implications, which raise new questions. Despite the potential for fecal origin of these Bacteroides, the phylogenetic relationship with enteric Bacteroides is remote, and we do not know whether the strains we observed are Cladophora-adapted, ubiquitous, or opportunistic. Other studies have shown that Bacteroides persist longer in marine habitats (Green et al. 2011); perhaps the environmental species are even more common in saltwater habitats. We believe that as further investigations are conducted, more examples of free-living Bacteroides will be found.

Fecal Bacteroides has been suggested as an indicator of wastewater pollution, with particular advantages over current indicators - enterococci and Escherichia coli-because (1) enteric Bacteroides are abundant in the human gut, and (2) it is generally believed that Bacteroides does not survive for long nor multiply in nature. Finding Cladophora-associated Bacteroides in this study suggests that bacterial pathogens may similarly persist and grow in Cladophora mats, potentially exposing swimmers during recreational activities. Thus, health risk studies are needed to better understand this problem since swimmers often encounter the decaying alga on beaches. 
This study demonstrates the long-term persistence and growth of Bacteroides in decaying Cladophora mats of southern Lake Michigan. It suggests that this is a general phenomenon in similar fresh- and marine-water environments with abundant filamentous algae or other nutrient sources. The observation of Bacteroides growing both in situ and in vitro and our genomic analyses supports this conclusion. If true, much work remains in our understanding of the common occurrence of viable environmental Bacteroides.

Acknowledgements. We thank K. Walsh, Z. Niec, J. Pruitt, and S. Miller for assistance in sample collection and laboratory analyses; thermal images of Cladophora mats were provided by $\mathrm{C}$. Weiskerger. We greatly appreciate R. Cornman and J. Adams, USGS, for helping to analyze sequencing data. We thank H. Solo-Gabriele, University of Miami, and C. Sinigalliano, NOAA, for their thoughtful reviews. Any use of trade, product, or firm names is for descriptive purposes only and does not imply endorsement by the US Government. This article is GLSC Contribution Number 1824 of the USGS Great Lakes Science Center.

\section{LITERATURE CITED}

> Bakunina IY, Nedashkovskaya O, Kim S, Zvyagintseva T, Mikhailov V (2012) Distribution of $\alpha$-N-acetylgalactosaminidases among marine bacteria of the phylum Bacteroidetes, epiphytes of marine algae of the Seas of Okhotsk and Japan. Microbiology 81:373-378

> Ballesté E, Blanch AR (2010) Persistence of Bacteroides species populations in a river as measured by molecular and culture techniques. Appl Environ Microbiol 76: 7608-7616

Baughn AD, Malamy MH (2004) The strict anaerobe Bacteroides fragilis grows in and benefits from nanomolar concentrations of oxygen. Nature 427:441-444

Bell A, Layton AC, McKay L, Williams D, Gentry R, Sayler GS (2009) Factors influencing the persistence of fecal Bacteroides in stream water. J Environ Qual 38: 1224-1232

> Bernhard AE, Field KG (2000) Identification of nonpoint sources of fecal pollution in coastal waters by using hostspecific 16S ribosomal DNA genetic markers from fecal anaerobes. Appl Environ Microbiol 66:1587-1594

Bower PA, Scopel CO, Jensen ET, Depas MM, McLellan SL (2005) Detection of genetic markers of fecal indicator bacteria in Lake Michigan and determination of their relationship to Escherichia coli densities using standard microbiological methods. Appl Environ Microbiol 71: 8305-8313

> Byappanahalli MN, Whitman RL (2009) Clostridium botulinum (type E) occurs and grows in the alga, Cladophora glomerata. Can J Fish Aquat Sci 66:879-882

Byappanahalli MN, Shively DA, Nevers MB, Sadowsky MJ, Whitman RL (2003) Growth and survival of Escherichia coli and enterococci populations in the macro-alga Cladophora (Chlorophyta). FEMS Microbiol Ecol 46: 203-211

Eichmiller JJ, Hicks RE, Sadowsky MJ (2013) Distribution of genetic markers of fecal pollution on a freshwater sandy shoreline in proximity to wastewater effluent. Environ Sci Technol 47:3395-3402

Falkow S, Rosenberg E, Schleifer K, Stackebrandt E (2006) The prokaryotes, Vol 7: Proteobacteria: delta and epsilon subclasses. Deeply rooting bacteria, 3rd edn. Springer, New York, NY

Green HC, Shanks OC, Sivaganesan M, Haugland RA, Field KG (2011) Differential decay of human faecal Bacteroides in marine and freshwater. Environ Microbiol 13: 3235-3249

Hehemann JH, Kelly AG, Pudlo NA, Martens EC, Boraston AB (2012) Bacteria of the human gut microbiome catabolize red seaweed glycans with carbohydrate-active enzyme updates from extrinsic microbes. Proc Natl Acad Sci USA 109:19786-19791

Hooper LV, Midtvedt T, Gordon JI (2002) How host-microbial interactions shape the nutrient environment of the mammalian intestine. Annu Rev Nutr 22:283-307

Ishii S, Yan T, Shively DA, Byappanahalli MN, Whitman RL, Sadowsky MJ (2006) Cladophora (Chlorophyta) spp. harbor human bacterial pathogens in nearshore water of Lake Michigan. Appl Environ Microbiol 72:4545-4553

> Kimura M (1980) A simple method for estimating evolutionary rates of base substitutions through comparative studies of nucleotide sequences. J Mol Evol 16:111-120

Kreader CA (1998) Persistence of PCR-detectable Bacteroides distasonis from human feces in river water. Appl Environ Microbiol 64:4103-4105

LaPara TM, Burch TR, McNamara PJ, Tan DT, Yan M, Eichmiller JJ (2011) Tertiary-treated municipal wastewater is a significant point source of antibiotic resistance genes into Duluth-Superior Harbor. Environ Sci Technol 45: 9543-9549

Layton A, Mckay LD, Williams D, Garrett V, Gentry R, Sayler G (2006) Development of Bacteroides 16S rRNA gene Taqman-based real-time PCR assays for estimation of total, human, and bovine fecal pollution in water. Appl Environ Microbiol 72:4214-4224

Liang Z, He Z, Zhou X, Powell CA, Yang Y, Roberts MG, Stoffella PJ (2012) High diversity and differential persistence of fecal Bacteroidales population spiked into freshwater microcosm. Water Res 46:247-257

> Liu C, Song Y, McTeague M, Vu AW, Wexler H, Finegold SM (2003) Rapid identification of the species of the Bacteroides fragilis group by multiplex PCR assays using group- and species-specific primers. FEMS Microbiol Lett 222:9-16

Madigan MT, Martinko JM, Parker J (2003) Brock biology of microorganisms, 10th edn. Prentice Hall, Pearson Education, Upper Saddle River, NJ

> Mauffret A, Mieszkin S, Morizur M, Alfiansah Y, Lozach S, Gourmelon M (2013) Recent innovation in microbial source tracking using bacterial real-time PCR markers in shellfish. Mar Pollut Bull 68:21-29

- Michel C, Macfarlane G (1996) Digestive fates of soluble polysaccharides from marine macroalgae: involvement of the colonic microflora and physiological consequences for the host. J Appl Bacteriol 80:349-369

Okabe S, Shimazu Y (2007) Persistence of host-specific Bacteroides-Prevotella 16S rRNA genetic markers in environmental waters: effects of temperature and salinity. Appl Microbiol Biotechnol 76:935-944

> Olapade OA, Depas MM, Jensen ET, McLellan SL (2006) Microbial communities and fecal indicator bacteria associated with Cladophora mats on beach sites along Lake 
Michigan shores. Appl Environ Microbiol 72:1932-1938

Savichtcheva O, Okayama N, Okabe S (2007) Relationships between Bacteroides 16S rRNA genetic markers and presence of bacterial enteric pathogens and conventional fecal indicators. Water Res 41:3615-3628

Seaman M (2009) Reuse options for Cladophora biomass. In: Proc Conf Cladophora and Lake Michigan beaches: community options for management workshop, 16 Jan 2009, University of Wisconsin, Oshkosh, WI

Shah H, Collins M (1989) Proposal to restrict the genus Bacteroides (Castellani and Chalmers) to Bacteroides fragilis and closely related species. Int J Syst Bacteriol 39:85-87 SPSS (2003) SPSS version 12. SPSS, Chicago, IL

Tamura K, Peterson D, Peterson N, Stecher G, Nei M, Kumar S (2011) MEGA5: molecular evolutionary genetics analysis using maximum likelihood, evolutionary distance, and maximum parsimony methods. Mol Biol Evol 28: 2731-2739

US Environmental Protection Agency (2010) Method B: Bacteroidales in water by TaqMan ${ }^{\circledR}$ quantitative polymerase chain reaction (qPCR) assay. US Environmental Protection Agency, Washington, DC

> van der Wielen PW, Medema G (2010) Unsuitability of quantitative Bacteroidales 16S rRNA gene assays for discerning fecal contamination of drinking water. Appl Environ Microbiol 76:4876-4881

> Verhougstraete MP, Byappanahalli MN, Whitman RL, Rose JB (2010) Cladophora in the Great Lakes: impacts on beach water quality and human health. Water Sci Technol 62:68-76

Vierheilig J, Farnleitner AH, Kollanur D, Bloschl G, Reischer GH (2012) High abundance of genetic Bacteroidetes

Editorial responsibility: Tom Fenchel,

Helsingør, Denmark markers for total fecal pollution in pristine alpine soils suggests lack in specificity for feces. J Microbiol Methods 88:433-435

> Vogel C, Rogerson A, Schatz S, Laubach H, Tallman A, Fell J (2007) Prevalence of yeasts in beach sand at three bathing beaches in South Florida. Water Res 41: 1915-1920

> Walters SP, Field KG (2006) Persistence and growth of fecal Bacteroidales assessed by bromodeoxyuridine immunocapture. Appl Environ Microbiol 72:4532-4539

Walters SP, Field KG (2009) Survival and persistence of human and ruminant-specific faecal Bacteroidales in freshwater microcosms. Environ Microbiol 11:1410-1421

Wexler HM (2007) Bacteroides: the good, the bad, and the nitty-gritty. Clin Microbiol Rev 20:593-621

Whitman RL, Shively DA, Pawlik H, Nevers MB, Byappanahalli MN (2003) Occurrence of Escherichia coli and enterococci in Cladophora (Chlorophyta) in nearshore water and beach sand of Lake Michigan. Appl Environ Microbiol 69:4714-4719

Wyatt KH, Rober AR, Schmidt N, Davison IR (2014) Effects of desiccation and rewetting on the release and decomposition of dissolved organic carbon from benthic macroalgae. Freshw Biol 59:407-416

> Yamahara KM, Layton BA, Santoro AE, Boehm AB (2007) Beach sands along the California coast are diffuse sources of fecal bacteria to coastal waters. Environ Sci Technol 41:4515-4521

- Yamahara KM, Sassoubre LM, Goodwin KD, Boehm AB (2012) Occurrence and persistence of bacterial pathogens and indicator organisms in beach sand along the California coast. Appl Environ Microbiol 78:1733-1745

Submitted: September 23, 2013; Accepted: February 6, 2014 Proofs received from author(s): March 22, 2014 